\title{
Alois Alzheimer and Gaetano Perusini: should man divide what fate united?
}

\author{
G. Macchi', C. Brahe ${ }^{2}$ and M. Pomponi ${ }^{3}$ \\ 1/stituto Neurologia; ${ }^{2}$ stituto Genetica Medica and ${ }^{3}$ /stituto Chimica e Chimica \\ Clinica, Catholic University, School of Medicine "A. Gemelli", Rome, Italy \\ Correspondence to: M. Pomponi, Istituto di Chimica e Chimica Clinica, Catholic \\ University, School of Medicine "A.Gemelli", Largo F. Vito, 1, 00168 Rome, Italy
}

\begin{abstract}
Three points of interest lie in considering how Alzheimer, and more significantly Perusini, struggled to throw light on the cause of this devastating disease. There is a stimulating possibility that Perusini believed presenile forms of Alzheimer's disease described the same disease as senile forms. If so this would anticipate current opinion, and reveal Perusini to dissent from Kraepelin. In addition, Perusini may have understood the pathological relationship between neuritic plaques and vascular changes, once more foreseeing the modern view of Alzheimer's disease. Finally, Perusini and Alzheimer disagreed with Jung's view concerning the relationship between neuropathology and clinical psychiatry. This point highlights the major change occurring at that time from classical neurology to the psychoanalytic era. In his last work (1911) Alzheimer quoted his Italian disciple many times, even speaking of 'Perusini's cases' (Perusinischen Fälle). This article is an attempt to change the eponym of Alzheimer's disease into the Alzheimer-Perusini disease. This is a brief history of a master and his disciple, whose scientific lives were, by events, divided.
\end{abstract}

Keywords: Alzheimer's disease - Gaetano Perusini - Emil Kraepelin.

This article originally appeared in European Journal of Neurology (1997), 4, 210-213

In 1986, Amaducci et al. described in detail the contribution of the Italian neuropathologist Gaetano Perusini (1879-1915) to the study and classification of Alzheimer's disease (Amaducci et al., 1986). Previously, in 1970, McMenemey recognized Perusini's contribution: "Perusini's four cases published in 1910 [even if already accepted for publication in 1908] were more straightforward ... Italian writers have understandably called it the Alzheimer-Perusini disease." (McMenemey, 1970).

In the foreword of their book The Early History of Alzheimer's Disease, Bick and Amaducci reported in 1987, "we have much more to learn ... we can see that the path was clearly outlined by these pioneers". These authors, generously, mentioned Gaetano Perusini and quoted two papers now available in English (Bick and Amaducci, 1987); the first study (Perusini, 1910) was originally in German while the second paper (Perusini, 1911) was translated from the Italian. At the beginning of the first Perusini study (54 pages and 79 figures contained in four tables) the author stated: "On sugges- tion of Dr. Alzheimer I have examined the four cases". It is a pity that the report did not contain a short appendix indicating the year in which Perusini started his study.

The early history of this disease dates back to when Alzheimer presented for the first time his famous case at the Psychiatric Convention of the South West German Society in Tubingen $(1906,1907)$. There was no discussion following his presentation and no headline or reference made to it in the Neurologische Centralblatt (1906). At the same meeting, Ludwig Frank (Zurich) and Bezzola (Schlo $\beta$ Hard) presented data regarding Freud's method and the application of this approach by his disciple, Jung (Burghölzli, Zurich). The subsequent discussion reported the contribution by Jung himself, Hoche (Freiburg), Isserlin (Heidelberg) and Gaupp (Tubingen). It is possible that Perusini was also present at Tubingen, considering that he was in Zurich during that year. He used to participate in interesting night meetings between very different schools, "die Somatiker und die Psychiker", which 
argued about the neuroanatomic (Constantin von Monakow) and the psychoanalytic (Bleuler, Jung) roles in the classification of mental illnesses (Perusini, 1909).

In 1911 Alzheimer proposed the separation of presenile and senile dementia, a question which is still a source of discussion to this day: "In 1906 I described a case of the disease ... because senile dementia was out of the question since the patient was only 56 years old". Interestingly, Perusini, who was a member of the same histopathological school, preferred to report the case described by his mentor in 1906 and three other cases of patients of 47, 67 and 63 years old (Perusini, 1910). By including the older patients, did Perusini doubt that the disease was a characteristic of presenium? If so, this would have foreshadowed the modern view and shown how Perusini differed from Kraepelin. It is possible that Kraepelin influenced Alzheimer to express views different from those of Perusini. In fact, Alzheimer himself appeared to be uncertain of how to explain the significance of his research (Alzheimer, 1911): "Perusini has pointed out that the fibrillary changes in nerve cells which I had described are also seen in severe cases of Dementia senilis". On the other hand, Kraepelin claimed that the form described by Alzheimer could not be considered senile dementia due to the age of onset (senium praecox) in spite of histopathological findings which were very similar to those found in the most serious forms of senile dementia. In conformity with his ideas, Kraepelin called it Alzheimer's disease. However, in another case, Perusini seemed to be closely connected with the Munich school. In fact, he believed (as did Alzheimer and Kraepelin) that the interpretation of the new disorder had to be different from the one given by Oskar Fischer (Fischer, 1910). This author considered the plaques as characteristic of a specific disorder, while being absent both in normal ageing and non-presbyophrenic disorders. Nevertheless, the integration plaques $=$ presbyophrenia was largely and easily disputed by numerous authors (Perusini, 1909; also references above). Moreover, Alzheimer added (Alzheimer, 1911): "Perusini's and Kraepelin's reservations against this integration have not been convincingly eliminated by Fischer's arguments". Notably, Alzheimer, in reporting his reservations against the integration plaques = presbyophrenia, cited Perusini ahead of Kraepelin. At the beginning of the 20th century, could a German researcher (Alzheimer) without reason quote an unknown Italian researcher (Perusini) ahead of his unquestionable master and "boss" (Kraepelin)? The only explanation is that Alzheimer's esteem of Perusini was such that he shared his views.
Still regarding this quarrel, Perusini (Perusini, 1910) stated:

"It is very likely that the plaques I have outlined are the same as those reported by Fischer and Hübner. Nevertheless it should be stressed that neither Fischer nor Hübner outlined the quite unique fibrillary changes. In my case histories, on the other hand, the concurrence of the fibrillary changes with the formation of the plaques is clearly an essential finding. ... What distinguishes findings in our cases from those of senile dementia are primarily quantitative differences ... even though we are partly dealing with pre-senile diseases...".

However, in 1911, Perusini was more explicit: "in the other cases, outlined by both Alzheimer and Perusini, the histopathological changes always were in agreement with those detected in the severest forms of senile dementia". This comment and the older patients of his study show that Perusini believed that presenile dementia and senile dementia were one disease. In 1911 Alzheimer showed high esteem and recognition when he stated: "Perusini believes that these cases characterize a distinct disease, partly for clinical and partly for histological reasons". Again, in the same year, Alzheimer said: "Fischer has given a complete account of Perusini's cases within his study". This is perhaps the best acknowledgement of Perusini's work: Alzheimer himself speaking of "Perusini's cases" (Perusinischen Fälle). Why does Alzheimer pay such a generous tribute to his disciple?

How can we call this disease Alzheimer's disease after this recognition and not Alzheimer-Perusini disease? Why is Alzheimer so generous with the young researcher? The following considerations made by Perusini are helpful as well as other fascinating theories contained in his study (Perusini, 1910) that are worth reporting:

"I believe that I can give evidence that the free plaques and those around the vessels ... must be considered identical ... pathological metabolic products of an unknown kind ... Luckily I was in a situation where I was able to examine the many preparations of Dr. Achùcarro ... morphologically, I have never seen in rabies such cells consisting only of entangled fibril bundles which are made up of fibrillary tangles that are often present in my case histories... we can perceive (naturally we can speak only of perception) that a kind of cement substance glued the fibrils together". 
Perusini became aware of the presence of something that is now known as $\beta$-amyloid peptide and which is enriched in intermolecular hydrogen bonding which leads to the $\beta$-pleated sheet structure and its characteristic low solubility. Still, "I believe that the progressive alteration of blood vessels... could be related mainly to the severe decomposition of the neuronal parenchyma". The relationship between the progressive alteration of blood vessels and the severe decomposition of the neurons is an enigma that is still a source of speculation to this day.

The young researcher also commented on the mechanism of the disease (Perusini, 1910) anticipating the modern considerations of AD: "Obviously, it remains an open question whether a noxious agent, which causes the whole disease, also acts on the blood vessels, or equally damages both the neuron and the blood vessels". In 1984, Wong et al., reported that the amyloid in neuritic plaques shares antigenic determinants with $\beta$-protein of the cerebrovascular amyloid. Perusini highlighted the first correlation between blood vessels changes and the decay of the neurons (Pomponi and Marta, 1992). These impressive comments, resulting from this young researcher's extraordinary scientific ability, would be sufficient justification for the eponym of Alzheimer-Perusini disease (Macchi, 1992).

Perusini also insisted on the tight link between mind and brain. In fact, he believed that the studies carried out by the Alzheimer school were very useful in demonstrating their close relationship and from which progress could be made in the knowledge of mental illness. He had faith in the histopathological study of the brain because these findings showed some remarkable data which were very important for clinical psychiatry and nosography of mental diseases (Perusini, 1911). On this point Perusini disagreed (as did the Munich school) with the non-organic causes of mental disease:

"The aphorism of Jung is that the pathological anatomy is useless. ... I believe that the pathology is the study of altered molecular processes ... the consciousness is bound to material cerebral processes ... depends on chemical physical law ... I believe that the Alzheimer studies show a close relationship between neuropathological and clinical psychiatry ..." (Perusini, 1909).

This not only highlights the major change occurring at that time from classical neurology to the psychoanalytic era but the echo is still present with similar debate in our time.

In conclusion, Alzheimer reported only one very uncertain case up until 1911 although Kraepelin had recorded "Alzheimer's disease" (Kraepelin, 1910). It is possible that Kraepelin was responsible for influencing Alzheimer and Perusini to differ in their views. Fate, however, had already bound their lives; both had strong roots in the upper classes (G.P. in the upper class and A.A. in the upper middle class); both were rich and united by a common interest in meticulous but ponderous neuropathological description. Moreover, Perusini could speak fluent German, his second mother tongue. In fact, the Perusinis lived in the small village of Cormóns in Friuli which, at that time, was part of the Austro-Hungarian empire. Andrea Perusini, Gaetano's father, was a good friend of the Habsburg bourgeoisie. In his castle (Rocca Bernarda) at Cormòns, there was a statue of Maximillian, brother of the emperor Francis Joseph. Furthermore, due to the socio-economic and scientific importance of the German language, he wanted a German governess from Munich for his sons. However, to comply with social conventions, he also wanted all three sons to be born in Udine (Regno d'Italia), where he had been physician and director of the city hospital since 1866 . Gaetano, his first son, was born in 1879. After receiving a degree in medicine at Rome University, he spent the majority of his years in neuropathological research in Munich and Zurich, where Perusini knew Jung (Perusini, 1909) and in Rome where he was the inseparable friend of Ugo Cerletti.

In 1912, Perusini's collaboration with Alzheimer ended. His master, in fact, had been called to the University of Breslau (Wroclaw), but at this point Alzheimer's scientific career ended, possibly for health reasons. The young Italian disciple no longer went to the psychiatric clinic in Munich and never again met with Alzheimer. However, fate, although indirectly, was to reunite them at the end of their lives. Perusini died on 8 December 1915, while helping some wounded soldiers (he received a silver medal for bravery in the First World War). He was buried in his hometown of Cormóns. Alzheimer died one month later, presumably from endocarditis. A few years later Nissl died too and an era ended. Freud's theories were triumphing.

It is a pity that scientists working in this field of research, particularly American neurologists, are unaware of Perusini's role in defining what we call Alzheimer's disease. However, we can still hope that McMenemey's acknowledgement will sooner or later be rediscovered.

\section{Acknowledgement}

The authors wish to thank Carolyn A. Waldron for editing the manuscript. 


\section{REFERENCES}

Alzheimer A (1906) Über einen eigenartigen schweren Ekrankungsprozeß der Hirnrinde. XXXVII Verammlung südwestdeutscher Irrenärzte in Tübingen am 3 and 4 Nov. Neurologische Centralblatt, 1134.

Alzheimer A (1907) Über eine eigenartige Erkrankung der Hirnrinde. Allgemeine Zeitschrift für Psychiatrie und Psychisch-Gerichtliche Medizin, LXIV, 146-148.

Alzheimer A (1911) Über eigenartige Krankheitsfaelle des späteren Alters. Zeitschrift für die gesamte Neurologie und Psychiatrie, Bd 4, Heft 3, 356-385.

Amaducci LA, Rocca WA and Schoenberg BS (1986) Origin of the distinction between Alzheimer's disease and senile dementia: how history can clarify nosology. Neurology, 36, 1497-1499.

Bick K and Amaducci L (1987) Foreword. In: The Early History of Alzheimer's Disease (Eds K Bick, L Amaducci and G Pepeu), p. 8, Padova, G Liviana Editrice.

Fischer O (1910) Die presbyophrene Demenz, deren anatomische Grundlage und klinische Abgrenzung Miliare Zeitschrift für die gesamte Neurologie und Psychiatrie, Bd 3, Heft 4, 471- 479.

Kraepelin E (1910) Psychiatrie: ein Lehrbuch für Studierende und Ärze. Leipzig, Barth.

Macchi G (1992) An historical and up-to-date contribution of Italian scientists to the understanding of pathology of Alzheimer's disease (AD) In: Alzheimer's Disease and Related Disorders (Eds M Nicolini, PF Zatta and B
Corain), Advances in the Biosciences, Vol. 87. Oxford, Pergamon.

McMenemey WH (1970) Alois Alzheimer and his disease. In: Alzheimer's Disease and Related Conditions (Eds GEW Wolstenholme and M O'Connor) pp. 5-9. London, Churchill (Ciba Foundation).

Perusini G (1909) Lanatomia patologica in psichiatria. Rivista Sperimentale di Freniatria, XXXV, 298-342.

Perusini G (1910) Über klinisch und histologisch eigenartige psychische Erkrankungen des späteren Lebensalters. Histologische und Histopathologische Arbeiten, Bd III, Heft 2, 197-351.

Perusini G (1911) Sul valore nosografico di alcuni reperti istopatologici caratteristici per la senilità. Rivista italiana di Neuropatologia, Psichiatria ed Elettroterapia, IV, 145-171 (there is an English translation of this paper in reference 4).

Pomponi M and Marta M (1992) "On the suggestion of Dr. Alzheimer I examined the following four cases." Dedicated to Gaetano Perusini. Ageing, Clinical and Experimental Research, 5, 135-139.

Wong CW, Quaranta V and Glenner GG (1984) Neuritic Plaques and cerebrovascular amyloid in Alzheimer disease are antigenically related. Proceedings of the National Academy of Sciences USA, 82, 8729-8732.

(Received 29 July 1996; accepted as revised 20 December 1996) 


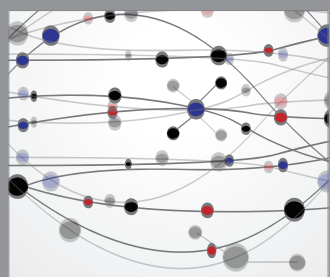

The Scientific World Journal
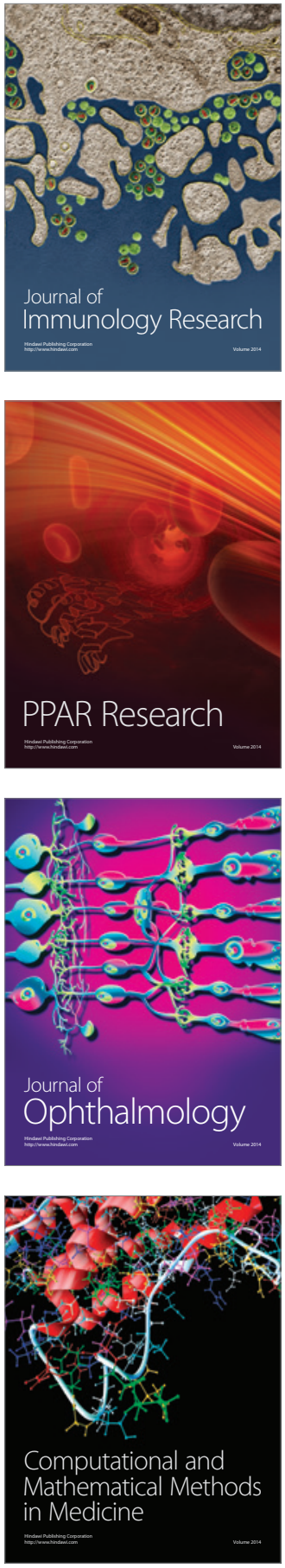

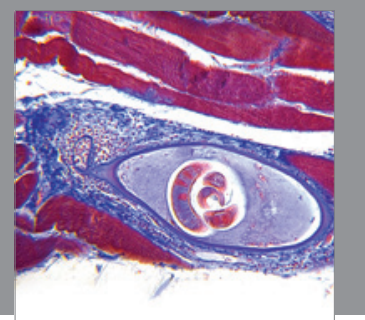

Gastroenterology

Research and Practice
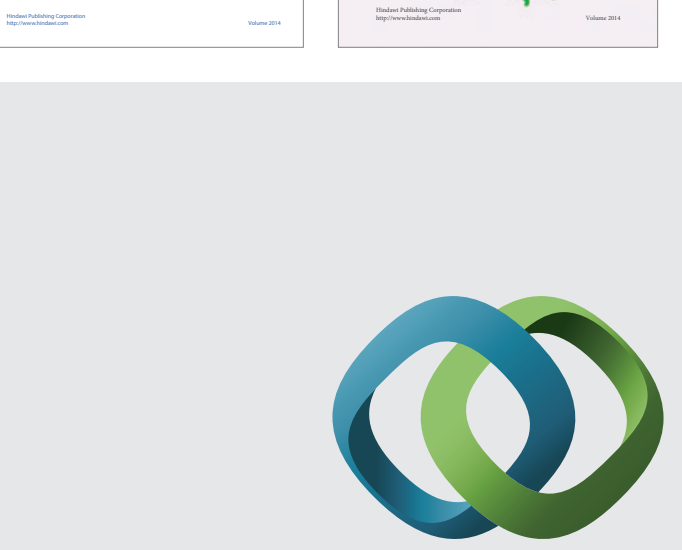

\section{Hindawi}

Submit your manuscripts at

http://www.hindawi.com
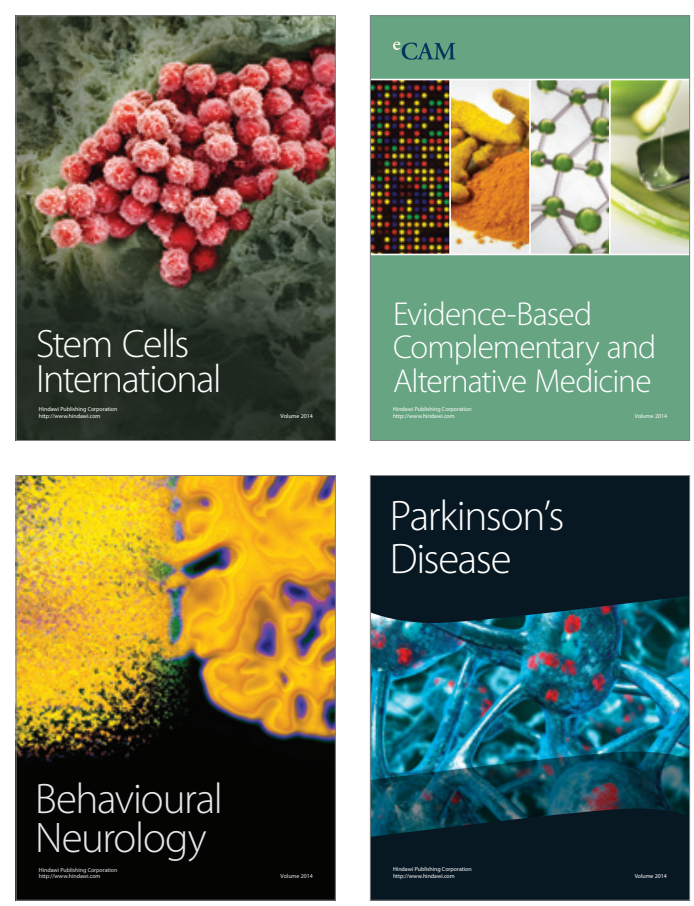

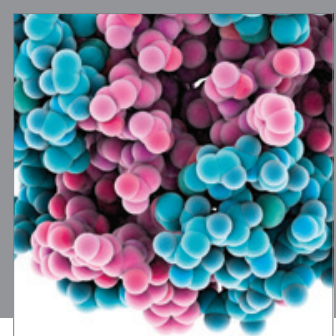

Journal of
Diabetes Research

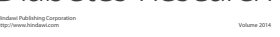

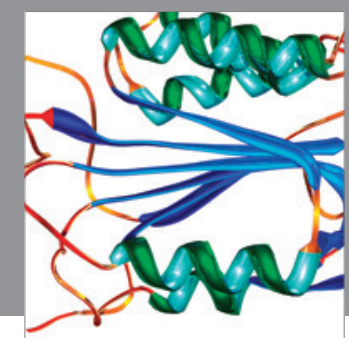

Disease Markers
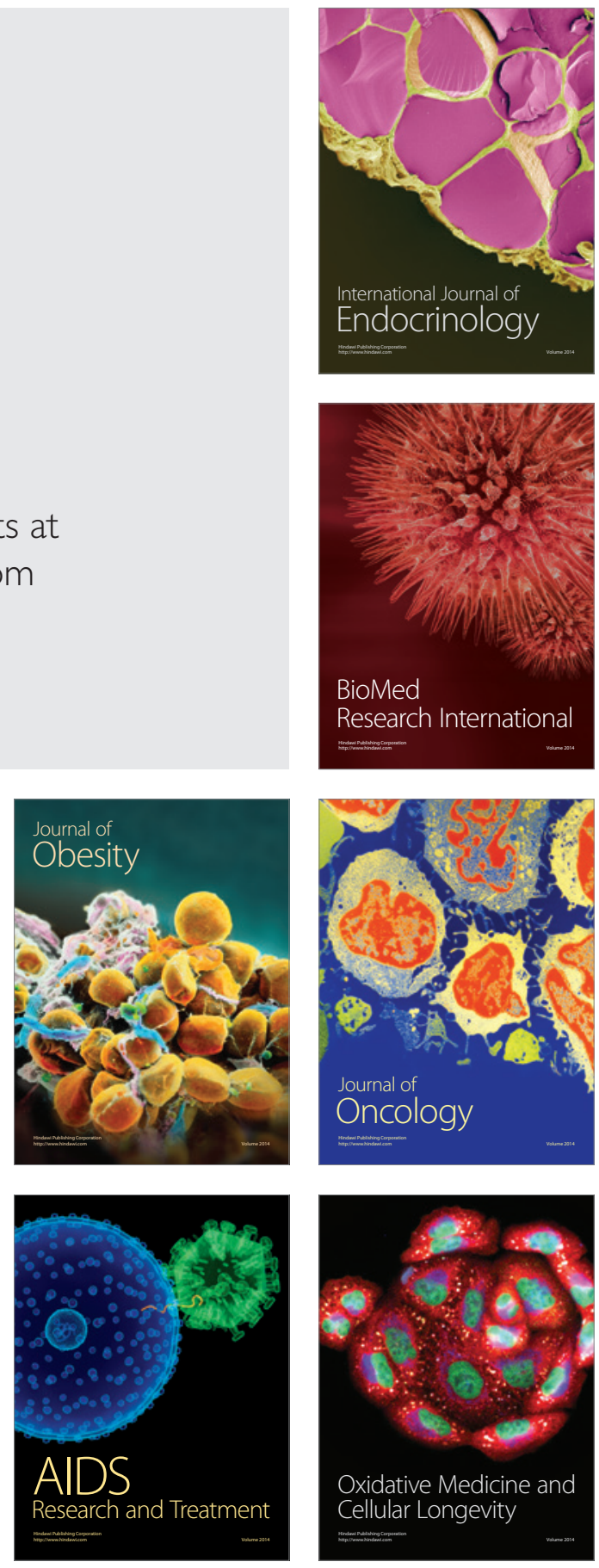